\title{
Tamanho dos alvéolos e aceitação de pães de forma enriquecidos com farelo de mandioca ${ }^{1}$
}

\author{
Gabriel Luis Castiglioni², Manoel Soares Soares Júnior², \\ Thaísa Anders Carvalho Souza ${ }^{2}$, Flávio Alves da Silva² ${ }^{2}$ Márcio Caliari ${ }^{2}$
}

\begin{abstract}
Alveoli size and acceptance of white

bread enriched with cassava bran

Given that solid and liquid residues are generated in the cassava processing, the present study aimed at using cassava bran to make bread. After a physico-chemical and microbiological analysis of cassava bran samples, five bread formulations, with substitution of wheat flour (WF) by dry cassava bran (DCB) between $0 \%$ and $20 \%$, were evaluated by analyzing the mean diameter of the dough alveoli, image and acceptance test. The

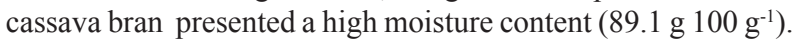
Thus, to use it in a safe way, concerning the microbiological aspect, the residue was dried, in order to provide a proper storage, before making the bread. The DCB samples showed no Bacillus cereus, thermotolerant coliforms and Salmonella sp. From the image analysis, it was found that the replacement of WF by DCB negatively affected the dough rise, being possible to suggest a model to describe the size variation of the breads alveoli, depending on the ingredients substitution level. The formulation with a $10 \%$ substitution of WF by DCB showed the best sensorial acceptability. It was possible to conclude that the use of DCB for making white bread is viable, from a technological, microbiological and sensorial point of view, and that it can improve economic and environmental aspects of industries that produce cassava starch.
\end{abstract}

KEY-WORDS: Manihot esculenta Crantz; industrial residue; cassava starch.

\section{INTRODUÇÃO}

O processo de produção de fécula de mandioca, qualquer que seja o grau de tecnologia empregado, consiste das etapas de lavagem e descascamento das raízes, trituração para a desintegração das células e liberação dos grânulos de amido, separação do farelo e do material solúvel e, finalmente, a secagem.

$\mathrm{O}$ processamento industrial da mandioca causa sérios problemas ambientais, pois mesmo as pequenas unidades fabris, como as casas de farinha

\section{RESUMO}

Considerando-se que, no processamento da mandioca, resíduos líquidos e sólidos são gerados, o presente estudo objetivou elaborar pães com farelo de mandioca. Após avaliação físico-química e microbiológica das amostras de farelo de mandioca, cinco formulações de pães, com níveis de substituição entre $0 \%$ e $20 \%$ de farinha de trigo (FT) por farelo de mandioca seco (FMS), foram avaliadas por meio do diâmetro médio dos alvéolos da massa, análise de imagem e teste de aceitação. $\mathrm{O}$ farelo de mandioca apresentou elevado teor de

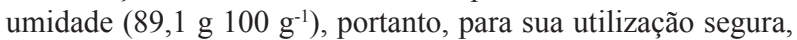
quanto ao aspecto microbiológico, foi realizada a secagem do resíduo, visando a garantir um armazenamento seguro, antes do processamento dos pães. As amostras de FMS apresentaram ausência de Bacillus cereus, coliformes termotolerantes e Salmonella sp. A partir da análise de imagem, verificou-se que a substituição de FT por FMS influenciou, negativamente, no crescimento da massa dos pães, sendo possível sugerir um modelo para descrever a variação do tamanho dos alvéolos dos pães, em função do nível de substituição dos ingredientes. A formulação que apresentou melhor aceitação sensorial foi aquela com $10 \%$ de substituição de FT por FMS. Concluiu-se que o uso do FMS, em pão de forma, é viável, do ponto de vista tecnológico, microbiológico e sensorial, podendo contribuir para a melhoria de aspectos econômicos e ambientais das indústrias produtoras de fécula de mandioca.

PALAVRAS-CHAVE: Manihot esculenta Crantz; resíduo industrial; fécula de mandioca.

e polvilheiras, geram quantidades significativas de resíduos sólidos e líquidos (Camargo et al. 2008).

$\mathrm{O}$ farelo de mandioca é rico nutricionalmente, com elevados teores de fibra alimentar total, solúvel e insolúvel, proteínas, cinzas e lipídios. Propriedades tecnológicas desejáveis, como maiores índices de absorção e solubilidade em água, são encontradas, quando compara-se o farelo com a fécula de mandioca. Além de possuir menor custo, por ser um resíduo, o farelo de mandioca pode tornar-se matéria-prima com características tecnológicas diferenciadas, para

1. Trabalho recebido em mar./2013 e aceito para publicação em mar./2014 ( $n^{\circ}$ registro: PAT 22890).

2. Universidade Federal de Goiás (UFG), Escola de Agronomia, Setor de Engenharia de Alimentos, Goiânia, GO, Brasil. E-mails: g_castigli@yahoo.com.br, mssoaresjr@hotmail.com, thaisanut@yahoo.com.br, flaviocamp@gmail.com, macaliari@ig.com.br. 
aplicação em alimentos como snacks, bolos, massas alimentícias, mingaus, sopas, cremes e alimentos infantis, dentre outros (Fiorda 2011, Souza 2011).

A indústria de alimentos tem promovido grande melhoria na oferta e qualidade de seus produtos, por meio do desenvolvimento de novas fontes alimentares e criação de alimentos inovadores. Economicamente, o uso de outras farinhas pode ser recomendável para substituir, parcialmente, a farinha de trigo na formulação de pães, quando esta não estiver disponível, ou necessitar ser importada (Embrapa 2003).

Estudos vêm sendo realizados com o intuito de desenvolver tecnologias de aproveitamento do bagaço de mandioca para a obtenção de produtos de elevado valor agregado, os quais poderiam ser utilizados como ingredientes em produtos alimentícios ricos em fibras e com segurança alimentar (Castiglione et al. 2013, Fiorda et al. 2013a, Fiorda et al. 2013b, Fiorda et al. 2013c, Souza et al. 2013). Entretanto, não foram encontradas na literatura pesquisas com a utilização do farelo de mandioca em pães de forma.

Em estudo realizado por Shittu et al. (2008), verificou-se que o volume e volume específico médio de pães (640-971 $\mathrm{cm}^{3}$ e 4,43-6,85 $\mathrm{g} \mathrm{cm}^{-3}$, respectivamente) podem variar significativamente, em função da proporção de farinha de trigo e fécula de mandioca. Resultados próximos a estes valores também foram reportados por Dwyer \& O'Halloran (1999), para pães elaborados somente com farinha de trigo.

Tendo-se em vista as observações anteriormente mencionadas e a aplicação de técnicas que possam facilitar a medição de alguns atributos de importância tecnológica, o presente estudo objetivou elaborar pães de forma, com substituição parcial da farinha de trigo (FT) por farelo de mandioca seco (FMS), visando ao aproveitamento deste resíduo como fonte de alimentação humana.

\section{MATERIAL E MÉTODOS}

O farelo de mandioca (cultivar IAC-12) utilizado foi doado pela Fecularia Bela Vista - Febela Ltda., situada no município de Bela Vista de Goiás (GO). As amostras foram coletadas na saída para o silo de armazenamento de farelo, em sacos de polietileno de baixa densidade. Após a coleta, as amostras foram transportadas, durante 40 minutos, para o laboratório, em caixas isotérmicas com gelo mineral, seguindo, imediatamente, para o processo de secagem e análises físico-químicas e microbiológicas.

As análises físico-químicas de seis amostras do farelo de mandioca in natura foram realizadas no Laboratório de Análises Físico-químicas de Alimentos da Escola de Agronomia da Universidade Federal de Goiás (UFG). O pH foi determinado com potenciômetro digital (Hanna Instruments, HI9224), devidamente calibrado com solução tampão pH 4 e 7 (IAL 2005); o teor de umidade pelo método gravimétrico, em estufa com circulação forçada de ar, a $105^{\circ} \mathrm{C}$, até peso constante (método 31.1.02); o teor de cinzas em forno mufla, a $550^{\circ} \mathrm{C}$, até combustão total da matéria orgânica (método 31.1.04); o extrato etéreo com éter de petróleo, em aparelho Soxlhet (método 31.4.02); e o nitrogênio total pelo método macro Kijdhal, com multiplicação pelo fator 6,25 , para obtenção do teor de proteína bruta (método 31.1.08), todos recomendados pela AOAC Internacional (1997).

Durante o processo de secagem das amostras de farelo de mandioca, as condições do ar foram mantidas à temperatura de $60^{\circ} \mathrm{C}$ e vazão de $0,019 \mathrm{~m}^{3} \mathrm{~kg}^{-1} \mathrm{~s}^{-1}$, durante 5 horas. Tais condições foram escolhidas previamente, para garantir a umidade da matéria-prima em, aproximadamente, $10 \%$. Utilizou-se secador convectivo (1,90 m x 0,80 m) de bandejas, com capacidade para 5 bandejas metálicas (55 cm x $57 \mathrm{~cm}$ cada). O farelo de mandioca seco (FMS) foi moído em moinho de rotor (Marconi, MA-090CFT) e peneirado em peneiras da série Tyler. O FMS coletado para uso no processamento dos pães apresentou granulometria entre 100 mesh e 200 mesh (0,152 $\mathrm{mm}$ e $0,075 \mathrm{~mm})$. Uma vez peneirado, o material foi embalado em sacos de polietileno de baixa densidade e mantido em ambiente seco e fresco.

As análises microbiológicas do FMS foram realizadas no Laboratório de Controle Higiênico-Sanitário de Alimentos (LACHSA) da Faculdade de Nutrição da UFG. Seis amostras, coletadas em três etapas diferentes, a intervalos de 30 dias, foram avaliadas quanto à contagem de Bacilus cereus, coliformes a $45^{\circ} \mathrm{C}$ e presença de Salmonella sp. (Brasil 2001). As amostras também foram avaliadas em função da contagem de bolores e leveduras e coliformes totais, pelo fato de ser matéria-prima ou conter matéria-prima proveniente do solo e ter contato direto com a terra.

As amostras embaladas foram colocadas em caixa isotérmica com gelo mineral, visando à manutenção da temperatura de $0^{\circ} \mathrm{C}$, durante o transporte de, 
aproximadamente, 40 minutos, para o laboratório. As análises seguiram as técnicas descritas pela American Public Health Association (APHA 2001).

Primeiramente, foram retirados $25 \mathrm{~g}$ da amostra (massa determinada em balança semianalítica). Esta subamostra foi transferida para saco plástico esterilizado e, em seguida, adicionaram-se $225 \mathrm{~mL}$ de água peptonada a $0,1 \%$, obtendo-se, após homogeneização por 2 minutos, a diluição $10^{-1}$. Desta diluição, foram obtidas as demais diluições $\left(10^{-2}\right.$ e $\left.10^{-3}\right)$. A semeadura foi realizada no prazo máximo de 10-15 minutos e o restante da amostra foi conservada sob refrigeração $\left(5^{\circ} \mathrm{C} \pm 1^{\circ} \mathrm{C}\right)$, caso houvesse necessidade de repetir a análise.

A contagem de Bacilus cereus foi realizada por meio de semeadura em superfície, sendo distribuído $0,1 \mathrm{~mL}$ de cada diluição em ágar manitol gema de ovo polimixina (MYP), adicionado de solução de gema de ovo a $50 \%$, com alças de Drigalsky. As placas foram incubadas a $37^{\circ} \mathrm{C}$, por $24-48$ horas. Das colônias consideradas suspeitas, foram realizadas as seguintes provas: motilidade, redução do nitrato e beta-hemólise.

Na pesquisa de coliformes totais, foi distribuído $1,0 \mathrm{~mL}$ de cada diluição, no centro da placa de Petri, e adicionados $15 \mathrm{~mL}$ de Ágar Cristal Violeta Vermelho Neutro Bile (VRBA), os quais foram homogeneizados e reservados, até a solidificação. As placas invertidas foram incubadas a $35^{\circ} \mathrm{C}$, por $24-48$ horas. Posteriormente, foram selecionadas as placas com 10 a 150 colônias, para realizar a confirmação. Com a alça de platina, foram inoculadas 3-5 colônias, em tubos contendo Caldo Verde Brilhante Bile 2\% de lactose, os quais foram incubados a $35^{\circ} \mathrm{C}$, por 48 horas.

A pesquisa de coliformes termotolerantes $\left(45^{\circ} \mathrm{C}\right)$, dentre os totais, foi feita por meio de provas, a partir das placas de VRBA utilizadas na contagem dos coliformes totais. Selecionaram-se 3-5 colônias típicas, que foram inoculadas em tubos com caldo para E. Coli (caldo EC), incubados a $44,5^{\circ} \mathrm{C}$, por 24 horas. A partir do caldo EC, foram realizadas provas do Indol, Vermelho de Metila, Voges-Proskauer e Citrato (IMVIC).

Para a pesquisa de Salmonella sp., realizou-se, primeiramente, o pré-enriquecimento (mistura de $25 \mathrm{~g}$ da amostra com $225 \mathrm{~mL}$ de água peptonada a $1 \%$ tamponada) e incubação a $35^{\circ} \mathrm{C}$, por 24 horas. $\mathrm{Na}$ solução de enriquecimento seletivo, pipetaram-se alíquotas de $1 \mathrm{~mL}$, as quais foram transferidas para um tubo contendo $10 \mathrm{~mL}$ de caldo tetrationato e outro com caldo selenito cistina. Os tubos foram incubados a $43^{\circ} \mathrm{C}$, por 24 horas, em banho-maria. A solução originada foi isolada em ágar seletivo. A partir dos caldos de enriquecimento seletivo, o inóculo foi semeado por estrias, em placas com ágar para Salmonella-Shigella (SS) e ágar Xilose-Lisina-Desoxicolato (XLD), e incubado a $35^{\circ} \mathrm{C}$, por 24 horas, observando-se, posteriormente, a presença de colônias típicas. Quando constatou-se a presença de colônias típicas, procedeu-se à identificação dos sorovares.

Para bolores e leveduras, a semeadura também foi em superfície, inoculando-se $0,1 \mathrm{~mL}$ de cada diluição em placas contendo Ágar Batata (AB) acidificado até $\mathrm{pH} 3,5$, com solução de ácido tartárico 10\%. Em seguida, as placas com os inóculos foram incubadas em estufa a $25^{\circ} \mathrm{C}$, por 3-5 dias. Após este período, foram verificadas e quantificadas as contagens de bolores e leveduras.

O ensaio para verificar a viabilidade tecnológica e sensorial de substituição parcial da FT por FMS foi realizado no Laboratório de Panificação da Escola de Agronomia da UFG, de abril a maio de 2010. Utilizou-se delineamento inteiramente ao acaso, com cinco tratamentos $(0 \%, 5 \%, 10 \%, 15 \%$ e $20 \%$ de substituição de FT por FMS) e quatro repetições, totalizando 20 unidades experimentais. Também fizeram parte das formulações: fermento biológico

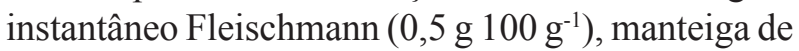

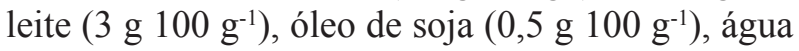

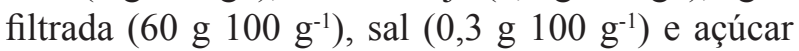
$\left(10 \mathrm{~g} 100 \mathrm{~g}^{-1}\right)$. As quantidades destes ingredientes foram mantidas em todas as formulações elaboradas.

Inicialmente, foi preparada uma mistura de $5 \mathrm{~g}$ de fermento biológico instantâneo, $15 \mathrm{~g}$ de farinha de trigo e $250 \mathrm{~mL}$ de água a $30^{\circ} \mathrm{C}$. Após transcorridos 10 minutos, esta mistura foi homogeneizada aos demais ingredientes. Uma vez misturados todos os ingredientes, a massa permaneceu em repouso por 15 minutos, a $28^{\circ} \mathrm{C}$. Após este período, foi submetida ao processo manual de cilindragem e deixada em repouso nas formas, por mais 20 minutos. Em cada batelada, foi possível preparar dois pães de forma grandes (tamanho padrão de supermercado - $500 \mathrm{~g}$ ). Após o crescimento da massa, realizou-se o forneamento a $190^{\circ} \mathrm{C}$, durante 40 minutos, utilizando-se forno elétrico Mondial 30L FR-04.

As imagens foram capturadas com câmera digital Sony (Cyber-Shot DSC W610, 14.1MP), a uma distância de $30 \mathrm{~cm}$ do corte da seção transversal dos 
pães. A análise de imagem foi realizada com o auxílio do software UTHSCSA Image Tool for Windows, versão 3.0. Avaliou-se o grau de crescimento da massa, em função da medida $(\mathrm{mm})$ dos diâmetros dos alvéolos de cada pão, em três cortes diferentes da seção transversal.

A imagem foi analisada na região central, além das laterais esquerda e direita (inferior e superior, respectivamente), totalizando cinco áreas de $4 \mathrm{~cm}^{2}$ $(2 \mathrm{~cm} \times 2 \mathrm{~cm})$, cada uma. Isto foi feito para minimizar o erro analítico, pois, nas regiões periféricas, há tendência de os alvéolos serem menores. Em função de os alvéolos não apresentarem formato perfeitamente circular, foram testados diferentes tipos de filtros, para facilitar a seleção de cada alvéolo pelo software Image Tool. Os alvéolos que não foram selecionados após o uso dos filtros foram selecionados manualmente, para posterior medição dos seus diâmetros médios. Previamente, capturou-se a imagem de uma régua de precisão, para calibração das demais imagens, em milímetros, sendo, posteriormente, calculadas as médias dos diâmetros destes alvéolos.

Os pães de forma experimentais foram avaliados quanto à aceitação, no Laboratório de Análise Sensorial da EA-UFG, por meio de um ensaio sensorial, com delineamento de blocos ao acaso, sendo considerado cada provador um bloco. O teste de aceitação, aprovado pelo Comitê de Ética da UFG sob o protocolo $016 / 2010$, utilizou escala hedônica de nove pontos, sendo: 1 - Desgostei muitíssimo; 2 - Desgostei muito; 3 - Desgostei regularmente; 4 - Desgostei ligeiramente; 5 - Indiferente; 6 - Gostei ligeiramente; 7 - Gostei regularmente; 8 - Gostei muito; 9 - Gostei muitíssimo (Stone \& Sidel 1993).

A análise sensorial contou com a participação de 100 provadores não treinados, que receberam cinco amostras codificadas, dispostas em bandeja de forma monódica sequencial, para serem avaliadas de forma global, em cabines individuais. Juntamente com as amostras, foi servida água, para ser utilizada entre a degustação das amostras.

As médias, os desvios-padrão e os coeficientes de variação dos dados obtidos nas análises físico-químicas do FMS foram calculados. Os dados da variável diâmetro médio dos alvéolos (observados na seção transversal dos pães de forma experimentais) e os escores obtidos no teste de aceitação foram avaliados por meio de análise de variância e os coeficientes de determinação e do modelo preditivo calculados por análise de regressão, utilizando-se o utilitário Statistica 7.0 for Windows. A resposta pôde ser melhor visualizada por meio de gráfico de dispersão construído com o auxílio do programa Excel. Considerou-se o escore médio 6 de aceitação global como limite mínimo para atingir o grau de aceitação. Um gráfico de barras foi construído, para melhor visualização dos escores e do limite pré-estabelecido.

\section{RESULTADOS E DISCUSSÃO}

Elevados teores de umidade e baixos teores de proteína, extrato etéreo e cinzas foram encontrados no farelo de mandioca (Tabela 1). A média encontrada para o $\mathrm{pH}$ do farelo foi de $6,67( \pm 0,15)$, enquadrando-se nos padrões aceitáveis para fécula de mandioca (acima de 4,5).

Cereda (2001) explica que, nos processos de separação da fécula, o teor de umidade dos resíduos, como é o caso do farelo de mandioca, pode se apresentar maior que a própria matéria-prima (cerca de $85 \%)$. Resultado aproximado $(89,1 \%)$ também foi encontrado no presente trabalho, evidenciando a afirmação de Cereda (2001), no que diz respeito às características dos resíduos após o intumescimento do material com água, para facilitar a extração da fécula. Morais (2012) também obteve umidades médias elevadas, tanto para a casca residual como para a polpa de batata residual, após peneiramento e decantação da água de lavagem dos tubérculos processados em uma linha de processamento industrial

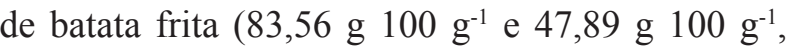
respectivamente), comprovando que o umedecimento da matéria-prima repercute diretamente nas características dos resíduos.

Jasko et al. (2011), após secagem de farelo de mandioca, encontraram valores de $11,5{\mathrm{~g} 100 \mathrm{~g}^{-1} \mathrm{de}}$ umidade; $0,1 \mathrm{~g} 100 \mathrm{~g}^{-1}$ de lipídios; $1,9{\mathrm{~g} 100 \mathrm{~g}^{-1} \mathrm{de}}$

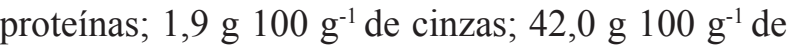
amido; e 18,7 g $100 \mathrm{~g}^{-1}$ de fibra bruta. Na caracterização de bagaço de mandioca, Camargo et al.(2008)

Tabela 1. Caracterização físico-química do farelo de mandioca in natura utilizado na formulação de pães de forma experimentais (Goiânia, GO, 2013).

\begin{tabular}{lccr}
\hline Componente & Valor $\left(\mathrm{g} 100 \mathrm{~g}^{-1}\right)$ & Desvio-padrão & $\mathrm{CV}(\%)$ \\
\hline Umidade & 89,10 & 1,10 & 1,23 \\
Proteína & 1,68 & 0,20 & 11,90 \\
Extrato etéreo & 0,97 & 0,08 & 8,25 \\
Cinzas & 1,85 & 0,22 & 11,89 \\
\hline
\end{tabular}




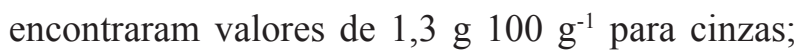

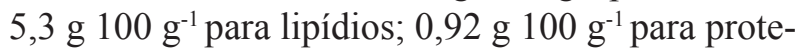
ínas; 79,32 g $100 \mathrm{~g}^{-1}$ para amido; e 9,9 g $100 \mathrm{~g}^{-1}$ para fibras. Portanto, são grandes as variações observadas na composição centesimal deste resíduo, principalmente no que se refere ao conteúdo de amido e fibra. As diferentes condições de processo, na extração da fécula de mandioca, são uma das principais explicações para este fato. Quanto mais otimizado for o processo de extração da fécula, menor variação na composição do bagaço de mandioca é encontrada. As variações nos teores podem estar associadas à origem, tipo de mandioca e, principalmente, ao processo envolvido (Fiorda et al. 2013a).

Nas análises microbiológicas do FMS, foi observada contagem inferior a $100 \mathrm{UFC} \mathrm{g}^{-1}$ para Bacillus cereus (considerado ausente), 1,3 x 10 $0^{5} \mathrm{UFG} \mathrm{g}^{-1}$ para coliformes totais e 7,6 x $10^{4} \mathrm{UFG} \mathrm{g}^{-1}$ para bolores e leveduras. Também, constatou-se a ausência de coliformes termotolerantes $\left(45^{\circ} \mathrm{C}\right)$ e Salmonella sp. A ausência de Bacillus cereus, Salmonella sp. e coliformes termotolerantes no FMS é muito positiva para sua aplicação na alimentação humana, uma vez que estes micro-organismos conferem grande risco de infecções, intoxicações ou toxinfecções alimentares (Vilhalva et al. 2011). Uma explicação para a ausência de tais micro-organismos pode ser o fato de a água de lavagem ser do próprio vegetal, pois, durante o processo de separação do amido, esta água é reaproveitada nas etapas de lavagem dos tubérculos, ao invés de ser direcionada para o tanque de tratamento de efluentes, o que, também, contribui para a economia de água e a redução do impacto ambiental causado pela empresa Febela Ltda.

A presença de micro-organismos indicadores em alimentos pode fornecer informações sobre a ocorrência de contaminação fecal e a provável presença de patógenos, em um alimento, podendo, com isto, indicar condições sanitárias inadequadas, durante o processamento, produção e armazenamento (Silva Júnior 2005). Na Resolução da Diretoria Colegiada (RDC) n ${ }^{\circ} 12$ de 2001 da Anvisa, legislação que estabelece os padrões microbiológicos para alimentos, não se considera a contagem de coliformes totais e bolores e leveduras como parâmetro de qualidade, em farinhas e farelos. No item 10L, são exigidas somente as contagens de Bacilus cereus (máximo de $5 \times 10^{3} \mathrm{UFC} \mathrm{g}^{-1}$ ), coliformes a $45^{\circ} \mathrm{C}$ (máximo de $5 \mathrm{x}$ $10^{2} \mathrm{UFC} \mathrm{g}^{-1}$ ) e ausência de Salmonella sp., em $25 \mathrm{~g}$ de material (Brasil 2001).
A presença de bolores e leveduras também pode fornecer informações sobre as condições gerais de higiene no processamento da matéria-prima e sua qualidade. Medidas como a implantação de boas práticas de fabricação, nas fecularias, poderiam amenizar problemas de contaminação.

Após o processo de secagem do FMS, as condições microbiológicas permaneceram em níveis satisfatórios, para sua posterior moagem e utilização na elaboração dos pães de forma. Este é um fator importante na etapa do processamento, visto que a segurança e qualidade dos ingredientes são de fundamental importância para a elaboração de produtos diferenciados.

Souza (2011), em estudo utilizando farelo de mandioca, encontrou valores de contagem de coliformes totais variando de $3,19 \times 10^{3}$ a $5,13 \times 10^{5}$ UFC e contagem de bolores e leveduras entre $1,9 \times 10^{3} \mathrm{e}$ $2,2 \times 10^{5}$. Estes resultados foram observados no produto in natura, armazenado à temperatura ambiente durante 72 horas. Tais valores foram semelhantes aos obtidos no presente trabalho.

Após a elaboração dos pães com substituição parcial da farinha de trigo por FMS, observou-se que a aparência destes assemelhou-se à dos pães integrais comumente encontrados em estabelecimentos comerciais. Vanzin et al. (2002), ao substituírem 10\% de farinha de trigo por FMS, em biscoitos, observaram que os biscoitos apresentaram características de sabor e aparência muito semelhantes às de biscoitos integrais. Isto, provavelmente, se deve ao fato de o farelo de mandioca ser um subproduto com alto teor de fibras de boa qualidade (Leonel 2001).

Durante a formulação dos pães, observou-se que a quantidade de FMS, em substituição à FT, proporcionou diferenciação no tamanho dos alvéolos do pão (Figuras 1 e 2). Com isto, foi possível estabelecer uma regressão entre o tamanho dos alvéolos e o nível de substituição de FT por FMS utilizado na formulação dos pães de forma experimentais.

Nas cinco formulações de pães, os diâmetros médios dos alvéolos foram $2,84 \mathrm{~mm}( \pm 1,77)$; $2,21 \mathrm{~mm}( \pm 0,93) ; 1,47 \mathrm{~mm}( \pm 0,61) ; 1,07 \mathrm{~mm}$ $( \pm 0,40)$; e $0,96 \mathrm{~mm}( \pm 0,42)$, quando acrescidos de $0 \%, 5 \%, 10 \%, 15 \%$ e $20 \%$ de FMS, respectivamente. A substituição da farinha de trigo pelo FMS influenciou, significativamente, no crescimento dos pães $(\mathrm{p}<0,05)$. À medida em que a formulação apresentou maior grau de substituição de farinha de trigo por FMS, menor foi o diâmetro médio obtido dos alvéo- 

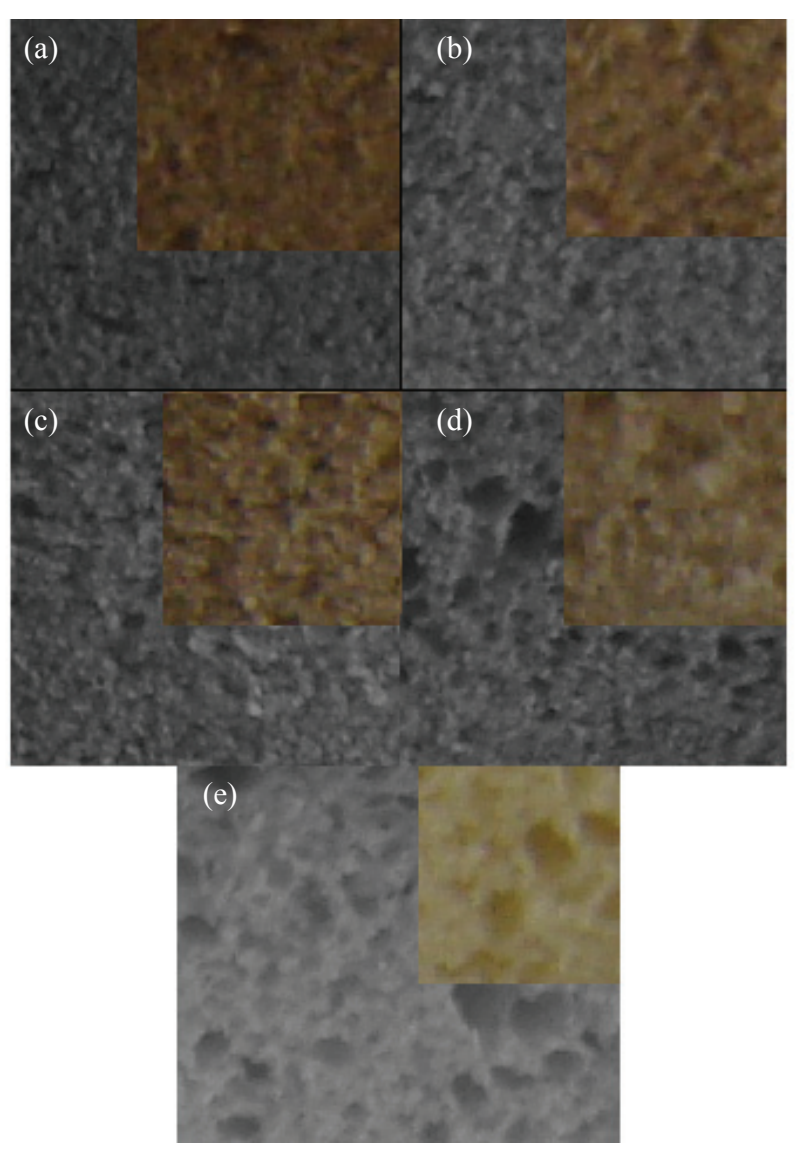

Figura 1. Cor e tamanho dos alvéolos dos pães elaborados com $20 \%$ (a), $15 \%$ (b), 10\% (c), 5\% (d) e sem substituição (e) de farinha de trigo por farelo de mandioca seco (Goiânia, GO, 2013).

los (Figura 2). Tais resultados evidenciam diferença significativa no volume e aumento nos alvéolos dos pães, quando a farinha de trigo é substituída por FMS.

Em relação ao teste sensorial, ocorreu ligeiro aumento do escore médio para aceitação global até 10\% de substituição de FT por FMS, na formulação dos pães de forma experimentais (Figura 3), permanecendo os escores médios entre "gostei ligeiramente" e "gostei regularmente". Os pães com $15 \%$ e $20 \%$ de substituição de FT por FMS não atingiram o escore mínimo (6) pré-estabelecido para serem considerados aceitos pelos julgadores, com escore médio entre "indiferente" e "gostei ligeiramente". A maior aceitação (escore 6,67) foi encontrada nas amostras em que $10 \%$ da farinha de trigo foi substituída por FMS.

Tais resultados poderiam ser ainda melhores, visto que não foi utilizado nenhum tipo de complemento nos pães (manteiga, geleia, etc.). Isto, provavelmente, influenciou na diminuição das notas, visto

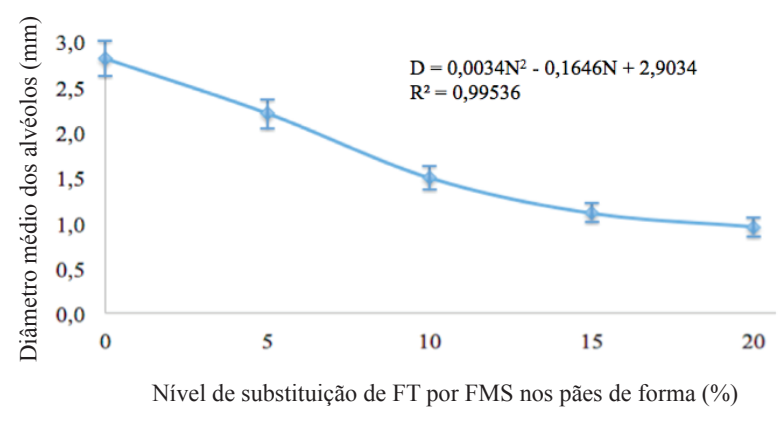

Figura 2. Diâmetro médio dos alvéolos, em função da percentagem de substituição de farinha de trigo (FT) por farelo de mandioca seco (FMS), na formulação de pães de forma experimentais (Goiânia, GO, 2013). D: diâmetro médio do alvéolo; N: nível de substituição de FT por FMS.

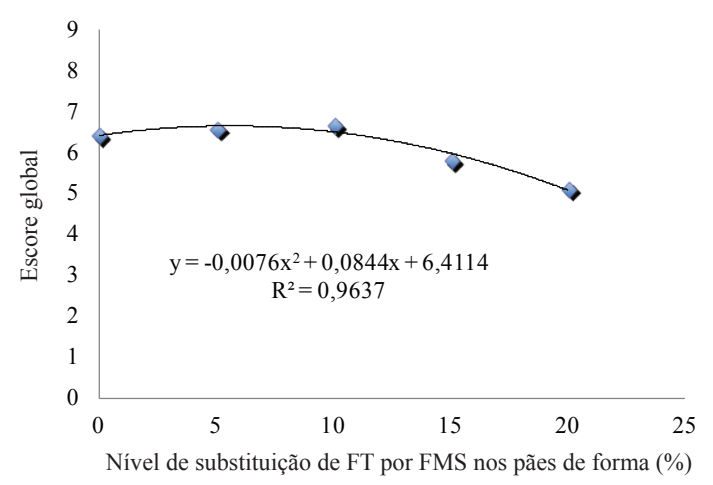

Figura 3. Aceitação global dos pães de forma experimentais, em função do nível de substituição de farinha de trigo (FT) por farelo de mandioca seco (FMS), utilizando-se a seguinte escala hedônica: 1 - Desgostei muitíssimo; 2 - Desgostei muito; 3 - Desgostei regularmente; 4 - Desgostei ligeiramente; 5 - Indiferente; 6 - Gostei ligeiramente; 7 - Gostei regularmente; 8 - Gostei muito; 9 - Gostei muitíssimo (Goiânia, GO, 2013).

que o padrão normal de consumo deste produto não é na forma pura. A escolha de se avaliar sensorialmente o produto puro se deu com a intenção de não mascarar o sabor original do pão.

Pesquisas que buscam o desenvolvimento de tecnologias para o aproveitamento do farelo de mandioca vêm sendo realizadas, visando à elaboração de produtos com maior valor agregado (Sriroth et al. 2000). Tal observação também foi confirmada no presente trabalho, pois o FMS apresentou alto potencial para elaboração de pães de forma, com pouco sabor residual.

Dentro do contexto tecnológico de uso de farinhas, vários são os produtos de panificação processados, dentre eles bolos, pães e biscoitos. Estudo 
realizado por Souza (2011) mostra que a substituição de farinha de arroz por farinha da casca e de farelo de mandioca, em bolos, apresentou ponto de corte com escore 6, nos testes de aceitação. Vilhalva et al. (2011), avaliando a qualidade de pães com substituição parcial de farinha de trigo por farinha de casca de mandioca também encontraram aceitação satisfatória em todas as formulações de pães estudadas. Os resultados positivos encontrados no teste sensorial dos pães demonstram a provável aceitação do mercado, no que se refere àqueles indivíduos com restrições alimentares e preocupados com a saúde, uma vez que tais produtos apresentam teor elevado de fibras.

No presente trabalho, não foi quantificado o teor de ácido cianídrico na matéria-prima seca, nem nos pães formulados. As condições de processamento às quais a matéria-prima foi submetida (secagem a $60^{\circ} \mathrm{C}$, com vazão de ar de $0,019 \mathrm{~m}^{3} \mathrm{~kg}^{-1} \mathrm{~s}^{-1}$, durante 5 horas e 40 minutos de forneamento a $190^{\circ} \mathrm{C}$ ) podem eliminar, por volatilização, este componente tóxico. Chisté et al. (2010) verificaram que o processamento da mandioca a $160^{\circ} \mathrm{C}$ é suficiente para garantir a qualidade alimentar do produto final, sem conferir risco à saúde do consumidor. Já Helbig et al. (2008) afirmam que, a $100^{\circ} \mathrm{C}$, durante 15 minutos, pode-se eliminar totalmente o ácido cianídrico.

\section{CONCLUSÕES}

1. O farelo de mandioca in natura apresentou alto teor de umidade e qualidade microbiológica condizente com o padrão mínimo exigido pela legislação brasileira, após o processo de secagem.

2. A análise de imagem, para determinação do tamanho dos alvéolos, mostrou ser um método simples e adequado para a avaliação do crescimento dos pães.

3. A formulação que apresentou melhor aceitação sensorial foi aquela com $10 \%$ de substituição da farinha de trigo por farelo de mandioca seco.

4. O uso do farelo de mandioca, após sua secagem, em pão de forma é viável, do ponto de vista tecnológico, microbiológico e sensorial, podendo contribuir com os aspectos econômicos e ambientais das indústrias produtoras de fécula de mandioca.

\section{REFERÊNCIAS}

AMERICAN PUBLIC HEALTH ASSOCIATION (APHA). Compendium of methods for microbiological examination of foods. 4. ed. Washington, DC: Downes FP, 2001.

AOAC INTERNATIONAL. Official methods of analysis of AOAC International. 3. ed. Maryland: AOAC International, 1997.

BRASIL. Agência Nacional de Vigilância Sanitária. Resolução RDC ${ }^{\circ} 12$, de 02 dejaneiro de 2001. Regulamento técnico sobre padrões microbiológicos para alimentos. 2001. Disponível em: <http://portal.anvisa.gov.br/wps/ $\mathrm{wcm} /$ connect/a47bab8047458b909541d53fbc4c6735/ RDC_12_2001.pdf?MOD=AJPERES $>$. Acesso em: 20 fev. 2013 .

CAMARGO, K. F. et al. Produção de biscoitos extrusados de polvilho azedo com fibras: efeito de parâmetros operacionais sobre as propriedades físicas. Ciência e Tecnologia de Alimentos, Campinas, v. 28, n. 3, p. 586591, 2008.

CASTIGLIONI, G. L. et al. Modelagem matemática do processo de secagem da massa fibrosa de mandioca. Revista Brasileira de Engenharia Agrícola e Ambiental, Campina Grande, v. 17, n. 9, p. 987-994, 2013.

CEREDA, M. P. Caracterização de subprodutos da industrialização da mandioca. In: CEREDA, M. P. (Coord.). Manejo, uso e tratamento de subprodutos da industrialização da mandioca. São Paulo: Fundação Cargill, 2001. p. 13-37.

CHISTÉ, R. C. et al. Quantificação de cianeto total nas etapas de processamento das farinhas de mandioca dos grupos seca e d'água. Acta Amazonica, Manaus, v. 40, n. 1, p. 221-226, 2010.

DWYER, E. et al. Wheat flour properties and end product quality. Dublin: The National Food Centre, 1999.

EMPRESA BRASILEIRA DE PESQUISA AGROPECUÁRIA (Embrapa). A indústria do amido de mandioca. Brasília, DF: Embrapa, 2003. (Documentos, 6).

FIORDA, F. A. Bagaço e fécula de mandioca na elaboração de farinhas cruas e pré-gelatinizadas, snacks e macarrões instantâneos com amaranto. 2011. 187 f. Dissertação (Mestrado em Ciência e Tecnologia de Alimentos) - Escola de Agronomia, Universidade Federal de Goiás, Goiânia, 2011.

FIORDA, F. A. et al. Farinha de bagaço de mandioca: aproveitamento de um subproduto e comparação com a fécula de mandioca. Pesquisa Agropecuária Tropical, Goiânia, v. 43, n. 4, p. 1-9, 2013a.

FIORDA, F. A. et al. Microestructure, texture and colour of gluten-free pasta made with amaranth flour, cassava starch and cassava bagasse. Lebensmittel-Wissenschaft + Technologie/ Food Science + Technology, London, v. 54, n. 1, p. 132-138, 2013b. 
FIORDA, F. A. et al. Amaranth flour, cassava starch and cassava bagasse in the production of gluten-free pasta: technological and sensory aspects. International Journal of Food Science \& Technology, Amsterdam, v. 48, n. 9, p. 1977-1984, 2013c.

HELBIG, E. et al. Análise dos teores de ácidos cianídrico e fítico em suplemento alimentar: multimistura. Revista de Nutrição, Araraquara, v. 21, n. 3, p. 323-328, 2008.

INSTITUTO ADOLFO LUTZ (IAL). Métodos físicoquímicos para análise de alimentos: normas analíticas do Instituto Adolfo Lutz. 4. ed. Brasília, DF: Anvisa, 2005.

JASKO, A. C. et al. Caracterização físico-química de bagaço de mandioca in natura e após tratamento hidrolítico. Revista Brasileira de Tecnologia Agroindustrial, Ponta Grossa, v. 5, n. 1, p. 427-441, 2011.

LEONEL, M. O. O farelo: subproduto da extração da fécula de mandioca. In: FUNDAÇÃO CARGILL. Manejo, uso e tratamento de subprodutos da industrialização da mandioca. São Paulo: Fundação Cargill, 2001. p. 211-217.

MORAIS, G. M. B. Resíduos da industrialização de batata: aplicação na produção de farinhas, snacks, farinhas pré-gelatinizadas e massa alimentícia fresca sem glúten. 2012. 214 f. Dissertação (Mestrado em Ciência e Tecnologia de Alimentos) - Escola de Agronomia, Universidade Federal de Goiás, Goiânia, 2012.

SHITTU, T. A. et al. Bread from composite cassava-wheat flour. II: Effect of cassava genotype and nitrogen fertilizer on bread quality. Food Research International, Toronto, v. 41, n. 1, p. 569-578, 2008.
SILVA JÚNIOR, E. A. Manual de controle higiênicosanitário em alimentos. 6. ed. São Paulo: Varela, 2005.

SOUZA, T. A. C. Segurança microbiológica de resíduos sólidos de fecularia de mandioca e aplicação em bolos para a alimentação humana. 2011. 87 f. Dissertação (Mestrado em Ciência e Tecnologia de Alimentos) - Escola de Agronomia, Universidade Federal de Goiás, Goiânia, 2011.

SOUZA, T. A. C. et al. The effect of chemical treatments on the $\mathrm{pH} \&$ microbial flora of cassava residues during storage. Food Science and Technology, Campinas, v. 33, n. 3, p. 457-462, 2013.

SRIROTH, K. et al. Processing of cassava waste for improved biomass utilization. Bioresource Technology, Miramar, v. 71, n. 1, p. 63-69, 2000.

STONE, H.; SIDEL, J. L. Sensory evaluation practices. 2. ed. London: Academic Press, 1993.

VANZIN, V. et al. Aproveitamento da massa residual obtida na extração de fécula de mandioca para elaboração de biscoitos com alto teor de fibras. In: ENCONTRO NACIONAL DE DIFUSÃO TECNOLÓGICA, 1., 2002, Medianeira. Anais... Medianeira: CEFET-PR, 2002. p. 162-163.

VILHALVA, D. A. A. et al. Aproveitamento da farinha de casca de mandioca na elaboração de pão de forma. Revista do Instituto Adolfo Lutz, São Paulo, v. 70, n. 4, p. 514-521, 2011. 